\title{
The characteristics of signal versus noise SST variability in the North Pacific and the tropical Pacific Ocean
}

Sang-Wook Yeh ${ }^{1}$ and Ben P. Kirtman ${ }^{2}$

${ }^{1}$ Center for Ocean-Land-Atmosphere Studies Institute of Global Environment and Society 4041 Powder Mill Rd., Suite 302 Calverton, MD 20705

2 George Mason University, Fairfax, Virginia, and Center for Ocean-Land-Atmosphere Studies Institute of Global Environment and Society 4041 Powder Mill Rd., Suite 302 Calverton, MD 20705

e-mail: swyeh@cola.iges.org

November, 2002 


\begin{abstract}
Total SST in a coupled GCM is diagnosed by separating the variability into signal variance and noise variance. The signal and the noise is calculated from multi-decadal simulations from the COLA anomaly coupled GCM and the interactive ensemble model by assuming both simulations have a similar signal variance. The interactive ensemble model is a new coupling strategy that is designed to increase signal to noise ratio by using an ensemble of atmospheric realizations coupled to a single ocean model. The procedure for separating the signal and the noise variability presented here does not rely on any ad hoc temporal or spatial filter. Based on these simulations, we find that the signal versus the noise of SST variability in the North Pacific is significantly different from that in the equatorial Pacific. The noise SST variability explains the majority of the total variability in the North Pacific, whereas the signal dominates in the deep tropics. It is also found that the spatial characteristics of the signal and the noise are also distinct in the North Pacific and equatorial Pacific.
\end{abstract}




\section{Introduction}

Atmospheric variability on seasonal-to-interannual time scales is often analyzed by separating it into an internal component due to atmospheric dynamics only and an external (or forced) component due to the variability of sea surface temperature (SST) forcing. Traditionally, these two modes of atmospheric variability have been identified by performing an ensemble of independent long-term simulations of the atmospheric response to observed or prescribed SST (Hannachi, 2001; Shukla et al., 2000; Straus and Shukla, 2000; Hoerling et al., 1997; Zwiers, 1996; Harzallah and Sadourny, 1995 among many others). An ensemble of atmospheric simulations is performed in which each integration, begun from different initial conditions, experiences the same evolution of the prescribed SST boundary condition. The forced variability is defined from the analysis of the ensemble mean and the internal variability is estimated by subtracting the ensemble mean from each ensemble member.

However, this method is limited to the analysis of atmospheric variables and can only be applied to separate an SST-forced signal and climate noise. Our goal here is to separate the SST variability into signal and noise component without any ad hoc temporal or spatial filter. This separation relies on a new strategy for coupling state-of-the-art oceanic general circulation models (OGCMs) and atmospheric general circulation models (AGCMs; Kirtman and Shukla, 2002). The standard coupled model has one AGCM coupled to one OGCM; however, this new interactive ensemble strategy has six realizations of the AGCM coupled to a single realization of the OGCM. As the interactive ensemble evolves, each AGCM realization experiences the same SST predicted by the OGCM. The OGCM, on the other hand, experiences surface fluxes that 
are the ensemble average of the six AGCM realizations. By comparing the variability of the interactive ensemble model with the standard coupled model, it is possible to separate the signal and noise in the total SST variability.

In constructing this separation it is assumed that the interactive ensemble technique reduces the noise, but has no impact on the signal. In this paper, we show the characteristics of the signal versus the noise SST variability in the North Pacific and the tropical Pacific Ocean. Our results show that the signal and the noise components of SST variability are markedly different in these two regions.

\section{Model}

The atmospheric component of the standard and interactive ensemble anomaly coupled model is the Center for Ocean-Land-Atmosphere Studies (COLA) AGCM with triangular truncation at total wave number 42 and 18 vertical levels. The ocean model is adapted from the Geophysical Fluid Dynamics Laboratory (GFDL) modular ocean model (Rosati and Miyakoda, 1988; Pacanowski et al., 1993) version 3 (MOM3). The component models are anomaly coupled in terms of heat, momentum and fresh water (Kirtman et al., 2002). The atmospheric initial states are taken from a 30 years simulation with observed SST, and are synoptically independent. Similarly, the ocean initial state is taken from a 30 years simulation with climatological surface fluxes. The coupling frequency of the model is once a day with daily mean values being exchanged between the ocean and the atmosphere. In order to separate the signal versus noise SST variability, the simulated SST from both the standard coupled model (hereafter, SC) and interactive 
ensemble model (hereafter, IE) are used. Both simulations have been run more than 200 years and all of the analysis shown here is based on the SST data for the last 200 years.

\section{Total SSTA variability in the Pacific}

Figure 1 shows the total SST anomaly (SSTA) variability for the observations and the SC model. The observed SST data are from January 1950 to December 2000 (Reynolds and Smith, 1994). The anomaly is defined as the deviation from the mean annual cycle calculated over the entire record for each field. The total SSTA variability both for the observations and SC model has two regions of prominent variability: a band of SSTA variability centered near $40^{\circ} \mathrm{N}$ and a narrow band of high variability in the equatorial region from $5^{\circ} \mathrm{S}-5^{\circ} \mathrm{N}$.

The band of strong SSTA variability centered near $40^{\circ} \mathrm{N}$ stretches from the coast of Asia into the central North Pacific for both the observations and SC model although the center of maximum SSTA variability is slightly shifted to the north in the SC model. This variability is closely connected to the dominant decadal SSTA variability in the North Pacific although it has also significant variability on interannual time scales. Based on filtered (Period $>7 \mathrm{yr}$ ) SST data taken from the COADS (Comprehensive OceanAtmosphere Data Set), Nakamura et al. (1997) found that there is strong decadal variability which was concentrated around the two major oceanic fronts within the North Pacific basin. The strongest variability is found around the subarctic front extending zonally at $42^{\circ} \mathrm{N}$. This region of variability is associated with the subpolar gyre including the Kuroshio-Oyashio extension (KOE). The second maximum of the variability nearly 
coincides with the subtropical front which is oriented from the northeast to the southwest. It is also known that the spatial pattern of the SSTA variability associated with the Pacific decadal oscillation is more zonally elongated and extends all the way across the North Pacific basin (Seager et al., 2001, Zhang et al., 1997; Tanimoto et al., 1997). Power spectra (not shown) from the SC model data yields significant decadal variability in the North Pacific region $\left(140^{\circ} \mathrm{E}-210^{\circ} \mathrm{E}, 35^{\circ} \mathrm{N}-45^{\circ} \mathrm{N}\right)$ which is in good agreement with the observations.

The SSTA variability in the equatorial Pacific is strongest between $5^{\circ} \mathrm{S}-5^{\circ} \mathrm{N}$ in both the SC model and the observations, although the model variability is weak and is too narrowly confined to the equator. This meridional scale problem in coupled GCMs has been noted in many other coupled simulations (e.g. Kirtman and Zebiak, 1997). Within the tropical Pacific basin, the variability is dominated by the El Nino-Southern Oscillation (ENSO) on the interannual time scales. The standard coupled model produces irregular ENSO events that are qualitatively similar to the observed in terms of their period and amplitude (Kirtman et al., 2002). Overall, the SC model has reasonably realistic simulation of the dominant decadal SST variability in the North Pacific and interannual variability in the equatorial Pacific.

\section{SST Signal versus Noise in the Pacific}

In separating the SST signal and the SST noise we make two assumptions. First, the signal is independent from the noise, therefore, the total SSTA variability can be represented as the sum of the signal and the noise. This approach is similar to the 
statistical tool which is employed to separate the total atmospheric variability of SSTforced signal and random internal variability in long-term ensemble simulations (Rowell, 1998 and many others). Second, we assume that the signal in the SC and the IE models is the same, and that the noise in the IE simulation is one sixth of the SC. This is because the IE simulation experiences surface fluxes that are the ensemble average of six atmospheric realizations. In essence, we assume that all the SST noise variability changes in proportion to the amplitude of the atmospheric noise variability. These assumptions lead us to the following decomposition of the total SSTA variability in the SC and the IE model.

$$
\begin{aligned}
& \text { Total SST variability: } S C=S+N \quad \text { (S: Signal, } N \text { : Noise) } \\
& \text { Total SST variability: } I E=S+N / 6 .
\end{aligned}
$$

Because we know the total SST variability in each case, the SST signal and the noise variability can be calculated from the above relationships. Despite the simplicity of this formulation, it is found that this decomposition is reasonable when applied to the wind stress, and is conservative when compared with the traditional approach for determining the signal and the noise (see the Appendix)

Based on the above formulation, Fig. 2 shows the spatial pattern of the signal and the noise SSTA variability in the North Pacific. The total SSTA variability in the North Pacific is almost entirely due to the noise except in the high latitude region above $50^{\circ} \mathrm{N}$. Nevertheless, there is some detectable signal in the North Pacific. The spatial structure of the signal and the noise have some interesting similarities. The SST signal variability has two regions showing prominent variance: (i) a band that extends from the east of Japan to the central North Pacific near of date line and (ii) a weaker signal that is orientated to the 
northeast-southwest in the region of $180^{\circ} \mathrm{E}-150^{\circ} \mathrm{W}, 30^{\circ} \mathrm{N}-40^{\circ} \mathrm{N}$. Similar to the signal variability, the noise SST variability has also its largest values in the above two regions. As mentioned above, these two regions in the North Pacific are also the regions with strong decadal SST variability, which are connected to major oceanic frontal zones with the subpolar and subtropical gyre, respectively.

Barnett et al. (1999) argued that the Kuroshio current, its extension, and the entire subtropical gyre are deeply involved in the Pacific decadal oscillation. Based on examining an ocean model forced by observed wind stress, Miller et al. (1998) showed that the North Pacific subpolar gyre, which is related to the KOE, and the subtropical gyre strengthened from the 1970s to the 1980s. Our result suggests that both oceanic gyres, which are closely connected to the North Pacific decadal variability are mostly associated with SSTA noise variability.

Figure 3 shows the ratio of the signal and the noise versus total SSTA variability in the North Pacific, respectively. The signal (noise) explains 10-20\% (80-90\%) of total SSTA variability in the North Pacific. This result suggests that stochastic midlatitude atmospheric forcing determines $80-90 \%$ of the SSTA variability in the North Pacific. Early studies of local ocean-atmosphere interaction by Davis (1976) and Frankignoul and Hasselmann (1977) suggested a red-noise type of correlation between atmospheric forcing and SST patterns, with the ocean responding passively to atmospheric forcing. Hasselmann (1976) also argued that an important feature of the climate system is the red noise oceanic response to white noise atmospheric forcing. Recent studies by many other investigators reached a similar conclusion that atmospheric forcing of the ocean played the dominant role. (Battisti et al. 1995; Delworth 1996; Saravanan and McWilliams 1997; 
Saravanan 1998). Our result indicates that this concept is valid for atmosphere-ocean interactions in the North Pacific.

Not surprisingly, the relative contribution of the signal versus the noise in the equatorial region is completely different compared to that of the North Pacific. Figure 4 is the same as in Fig. 2 except for the equatorial Pacific. In the deep Tropics, the signal dominates the noise; however, the signal to noise ratio falls rapidly poleward. In contrast to the North Pacific, the tropical atmosphere either has relatively less noise or the noise is relatively ineffective in forcing SSTA variability suggesting that tropical atmosphereocean system is more highly coupled.

In contrast to the signal and noise characteristics in the North Pacific, the spatial patterns of signal and the noise are different from each other in the equatorial Pacific. The signal is narrowly confined to the equator, whereas the noise is relatively less equatorially trapped in the eastern Pacific. Figure 5 shows the zonal and meridional structure of the signal and the noise variance averaged in $5^{\circ} \mathrm{N}-5^{\circ} \mathrm{S}, 120^{\circ} \mathrm{E}-90^{\circ} \mathrm{W}$, respectively. Note that the amplitude of the noise is indicated on the right of each panel and is a factor of two smaller that the signal. The signal variance is narrowly confined an equatorial band and it is dominant in two regions: one is the central Pacific around $180^{\circ} \mathrm{E}-150^{\circ} \mathrm{W}$ and the other is trapped in the far eastern coast of South America. On the other hand, the noise variability is less equatorially confined and is almost equal to the signal variance in the eastern Pacific between $150^{\circ} \mathrm{W}$ and $100^{\circ} \mathrm{W}$. These characteristics of the signal and the noise patterns are distinct from those of North Pacific where the signal and noise variance were collocated. It is also interesting to note that in the eastern Pacific, where the model 
variability is weak compared to observations, the noise variability is comparable to the signal.

\section{Concluding Remarks}

By using a new coupling strategy, we have devised a simple formulation for isolating SST signal and noise variance. This is a new approach for determining how much SST variability is signal and how much is noise and does not rely on ad hoc temporal or spatial filter. We briefly compared characteristics of the signal and the noise variability in the North Pacific and equatorial Pacific. The relative contribution of the signal versus the noise in the both Pacific regions is different. The noise (signal) SSTA variability dominates in the North (equatorial) Pacific.

Although there is a large difference in magnitude, both the signal and the noise in the North Pacific are concentrated to the two regions that are related to the major oceanic fronts. The signal variance and the noise variance are collocated. There is no consensus as to whether decadal variability in the midlatitudes involves a coupled ocean-atmosphere mode rather than merely reflecting forcing of the ocean by stochastic variability (Alexander 1992; Miller et al. 1994; Latif and Barnett 1994, 1996; Robertson 1996; Barnett et al., 1999). The result of the ratio of the signal and the noise versus the total SSTA variability suggests that the midlatitude ocean system is primarily responding to atmospheric noise and that the signal is quite small. This means that coupled oceanatmosphere processes are difficult to detect in the North Pacific, and even if detected, their contribution is on the order of $10-20 \%$ of the total variability. On the other hand, 
this result also suggests that there is coupled ocean-atmosphere variability in the North Pacific on the order of $10-20 \%$ of the total variance that may be predictable.

In contrast to the North Pacific, the tropical ocean-atmosphere system is highly coupled. Analysis of the spatial pattern of the variance indicates that the signal and the noise in the equatorial Pacific are out of phase. The region showing minimum signal variability is coincident to that of maximum noise variability in the equatorial band. The coupled model variability in the eastern Pacific is particularly weak compared to the observations. It is interesting to note that this is a region where the signal and noise variability are comparable. It is our speculation that since the thermocline simulation is particularly poor in this region, i.e., too close to the surface, the ocean is very sensitive to atmospheric noise. Another possible interpretation is that the SST is less predictable in the far eastern Pacific, which is becoming part of the conventional wisdom based on coupled model prediction. In other words, the NINO3.4 $\left(5^{\circ} \mathrm{N}-5^{\circ} \mathrm{S}, 170^{\circ} \mathrm{E}-120^{\circ} \mathrm{W}\right)$ index is more predictable than the NINO3 $\left(5^{\circ} \mathrm{N}-5^{\circ} \mathrm{S}, 150^{\circ} \mathrm{W}-90^{\circ} \mathrm{W}\right)$ index.

Acknowledgments: This work has benefited from comments from J. L. Kinter III. This research was supported by grants from the National Science Foundation ATM9814295 and ATM-0122859, the National Oceanic and Atmospheric Administration NA16-GP2248 and National Aeronautics and Space Administration NAG5-11656. 


\section{Appendix}

This appendix presents the signal and noise calculation applied on the zonal wind stress. Since this is atmospheric variable, it is available for each of the six ensemble members in the IE. The intent is to check the methodology introduced in section 4 against a more traditional approach. The traditional method for separating the signal and noise from the wind stress based on the six AGCM realizations in the IE model simulation. By

total variation, we mean the total sum of squares, $T S S=\sum_{N=1}^{6} \sum_{T}^{200 y r}\left(W S_{N T}-\overline{W S_{O O}}\right)^{2}$ of the monthly mean wind stress computed across all realizations and years. Here, $W S_{N T}$ indicates the monthly mean wind stress in each month $(T)$ of simulation $N$, and $\overline{W S_{O O}}$ is the ensemble climatology computed by averaging across all years and simulations. We used the two-way analysis of variance technique to calculate the noise variability (Zwiers, 1996). The noise variability measures the internal or natural variation of the variable and the signal is taken by subtracting the noise from the total variation (TSS).

$$
\begin{gathered}
\text { Noise }=\sum_{N=1}^{6} \sum_{T}^{200 y r}\left(W S_{N T}-\overline{W S_{O T}}-\overline{W S_{N O}}+\overline{W S_{O O}}\right)^{2} \\
\text { (here, } \left.\overline{W S_{O T}}=\sum_{N=1}^{6} W S_{N T}, \overline{W S_{N O}}=\sum_{T}^{200 y r} W S_{N T}\right)
\end{gathered}
$$

Figure A1 shows the spatial pattern of the signal and the noise variability for the zonal wind stress calculated from the traditional and our new method, respectively. The pattern of both the signal and the noise are very similar, but the magnitudes are more conservative using our approach. In other wards, the signal (noise) is smaller (larger) in our calculation. If we assume that the IE model has only signal (i.e., no noise), the magnitude of signal is similar as shown in Fig. Alb. We assert that our approach, which 
is more conservative, probably gives a more reasonable estimate of the signal and the noise. 


\section{Reference}

Alexander, M. A., 1992: Midlatitude atmosphere-ocean interaction during El Nino, I. The North Pacific Ocean. J. Climate, 5, 944-958.

Barnett, T. P., D. W. Pierce, R. Saravanan, N. Schneider, D. Dommenget, and M. Latif, 1999: Origins of the midlatitude Pacific decadal variability. Geophys. Res. Lett., 26, 1454-1456.

Battisti, D. S., U. S. Bhatt, and M. A. Alexander, 1995: A modeling study of interannual variability in the wintertime North Atlantic Ocean. J. Climate, 8, 3067-3083.

Davis, R. E., 1976: Predictability of sea surface temperature anomalies and sea level pressure anomalies over the North Pacific ocean. J. Phys. Oceanogr., 6, 249-266.

Delworth, T., 1996: North Atlantic interannual variability in a coupled ocean-atmosphere model. J. Climate, 9, 2356-2375.

Frankignoul, C., and K. Hasselmann, 1977: Stochastic climate models: Part I. Application to sea surface temperature anomalies and thermocline variability. Tellus, 29, 289-305.

Hannachi, A., 2001: Toward a nonlinear Identification of the atmospheric response to ENSO. J. Climate, 14, 2138-2149.

Hasselmann, K., 1976: Stochastic climate models: Part I. Theory. Tellus, 28, 473-485.

Harzallah, A., and R. Sadourny, 1995: Internal versus SST-forced Atmospheric variability as simulated by an atmospheric general circulation model. J. Climate, $8,474-495$.

Hoerling, M. P., A. Kumar, and M. Zhong, 1977: El Nino, La Nina, and the nonlinearity of their teleconnections. J. Climate, 10, 1769-1786.

Kirtman B. P., and J. Shukla, 2002: Interactive coupled ensemble: A new coupling strategy for CGCMs. Geophys. Res. Lett., 29, 1029-1032.

, Y. Fan and E. K. Schneider, 2002: The COLA global coupled and anomaly coupled ocean-atmosphere GCM. J. Climate, 15, 2301-2320.

, and, S. Zebiak, 1997: ENSO simulation and prediction with a hybrid coupled model. Mon. Wea. Rev., 125, 2620-2641.

Latif, M., and T. P. Barnett, 1994: Causes of decadal climate variability over the North Pacific and North America, Science, 266, 634-637. 
Miller, A. J., D. R. Cayan, and W. B. White, 1998: A westward-intensified decadal change in the North Pacific thermocline and gyre-scale circulation, J. Climate, 11, 3112-3127.

Nakamura, H., G. Lin, and T. Yamagata, 1997: Decadal climate variability in the North Pacific during the recent decades. Bull. Amer. Meteor. Soc., 78, 2215-2225.

Pacanowski, R. C., K. Dixon, and A. Rosati, 1993: The GFDL modular ocean model users guide, version 1.0. GFDL Ocean Group Tech Rep. No. 2, 77 pp. [Available from GFDL/NOAA Princeton University, Princeton NJ 08542].

Reynolds, R., and T. M. Smith, 1994: Improved global sea surface temperature analysis using optimum interpolation. J. Climate, 7, 929-948.

Robertson, A. W., 1996: Interdecadal variability over the North Pacific in a multi-century climate simulation. Clim. Dyn., 12, 227-241.

Rosati, A., and K. Miyakoda, 1988: A general circulation model for upper ocean circulation. J. Phys. Oceanogr., 18, 1601-1626.

Rowell, D. P., 1998: Assessing potential seasonal predictability with an ensemble of multidecadal GCM simulations, J. Climate, 11, 109-120.

Saravanan, R., 1998: Atmospheric low-frequency variability and its relationship to mildatitude SST variability: Studies and the NCAR Climate System Model. $J$. Climate, 11, 1386-1404.

, and J. C. McWilliams, 1995: Multiple equilibria, natural variability, and climate transitions in an idealized ocean-atmosphere model. J. Climate, 8, 2296-2323.

Seager, R., Y. Kushnir, N. H. Naik, M. A. Cane, and J. Miller, 2001: Wind-driven shifts in the latitude of the Kuroshio-Oyashio extensioin and generation of SST anomalies on decadal timescales. J. Climate, 15, 4249-4265.

Shukla, J and co-authors, 2000: Dynamical seasonal prediction., Bull. Amer. Meteor. Soc., 81, 2593-2606.

Straus D. M., and J. Shukla, 2000: Distinguishing between the SST-forced variability and internal variability in mid-latitudes: Analysis of observation and GCM simulations., Q. J. R. Meteorol. Soc., 126, 2323-2350.

Tanimoto, Y., N. Iwasaka, and K. Hanawa, 1997: Relationships between sea surface temperature, the atmospheric circulation and air-sea fluxes on multiple timescales, J. Meteor. Soc. Japan, 75, 831-849. 
Zhang, Y., J. M. Wallace, and D. S. Battisti, 1997: ENSO-like intedecadal variability: 1900-93. J. Climate, 10, 1004-1020.

Zwiers, F. W., 1996: Interannual variability and predictability in an ensemble of AMIP climate simulations conducted with the CCC GCM2. Climate Dyn., 12, 825-847. 


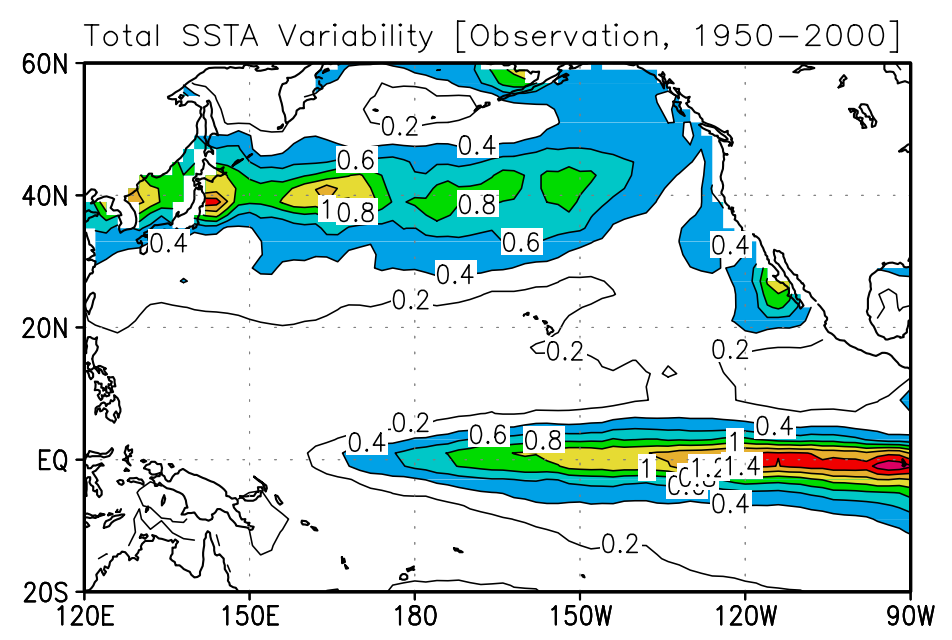

(a)

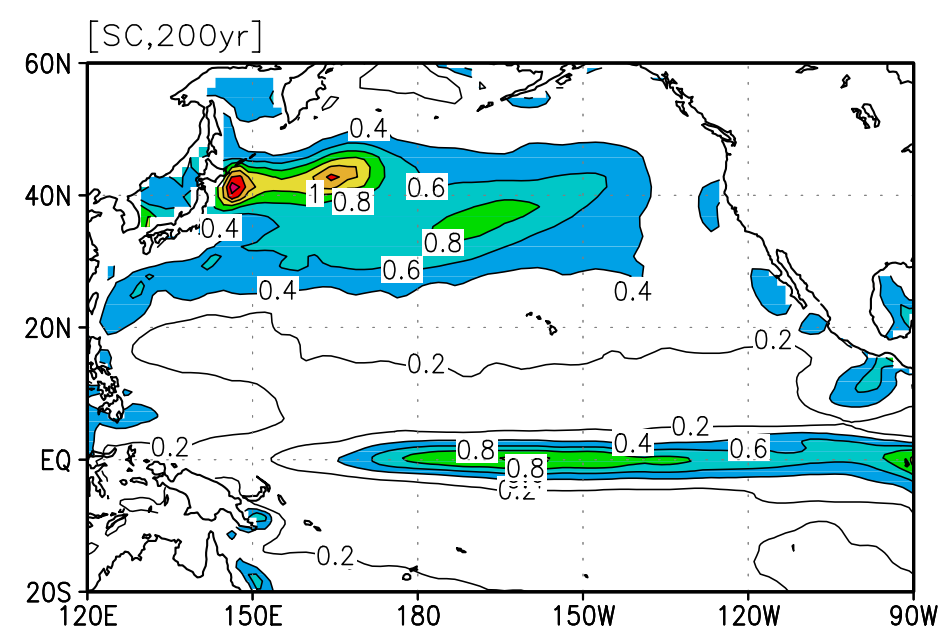

(b)

Figure 1. The total SSTA variability for the observations for the period of 1950-2000 (a) and (b) as in (a) except for the standard coupled model for the period of $200 \mathrm{yrs}$. Contour interval is $0.2\left[{ }^{\circ} \mathrm{C}\right]^{2}$. Shading is for above $0.4\left[{ }^{\circ} \mathrm{C}\right]^{2}$. 


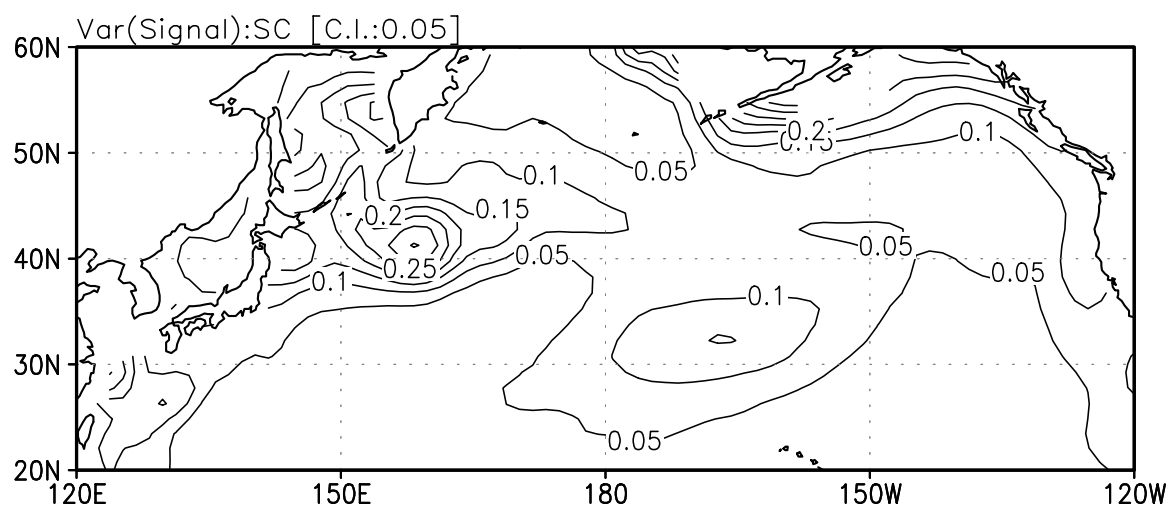

(a)

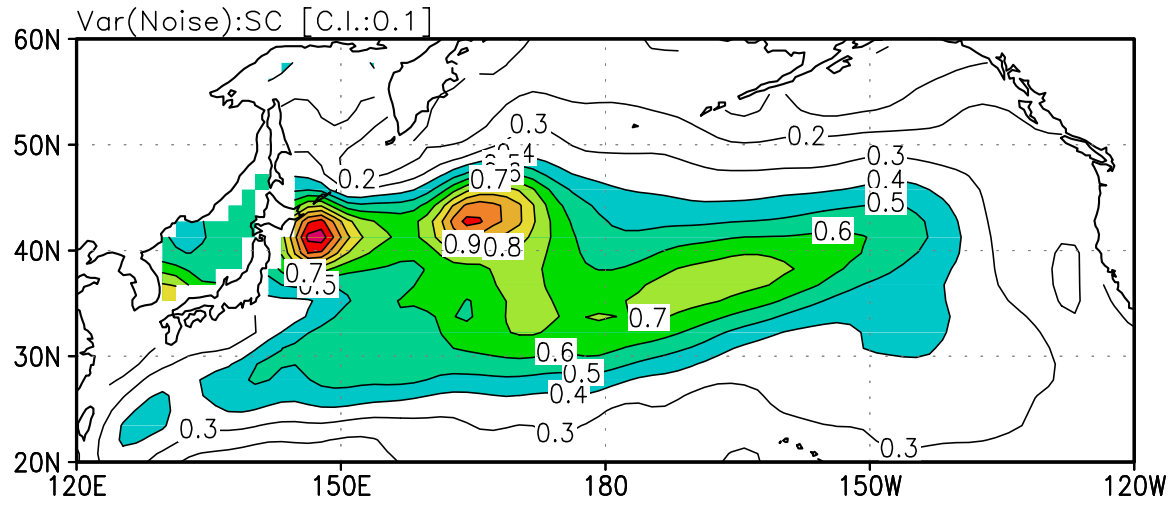

(b)

Figure 2. The spatial pattern of signal (a) and noise (b) SSTA variability for the North Pacific in the standard coupled model. Unit is $\left[{ }^{\circ} \mathrm{C}\right]^{2}$. Shading is for above $0.4\left[{ }^{\circ} \mathrm{C}\right]^{2}$. Note the different contour intervals on the two panels. 

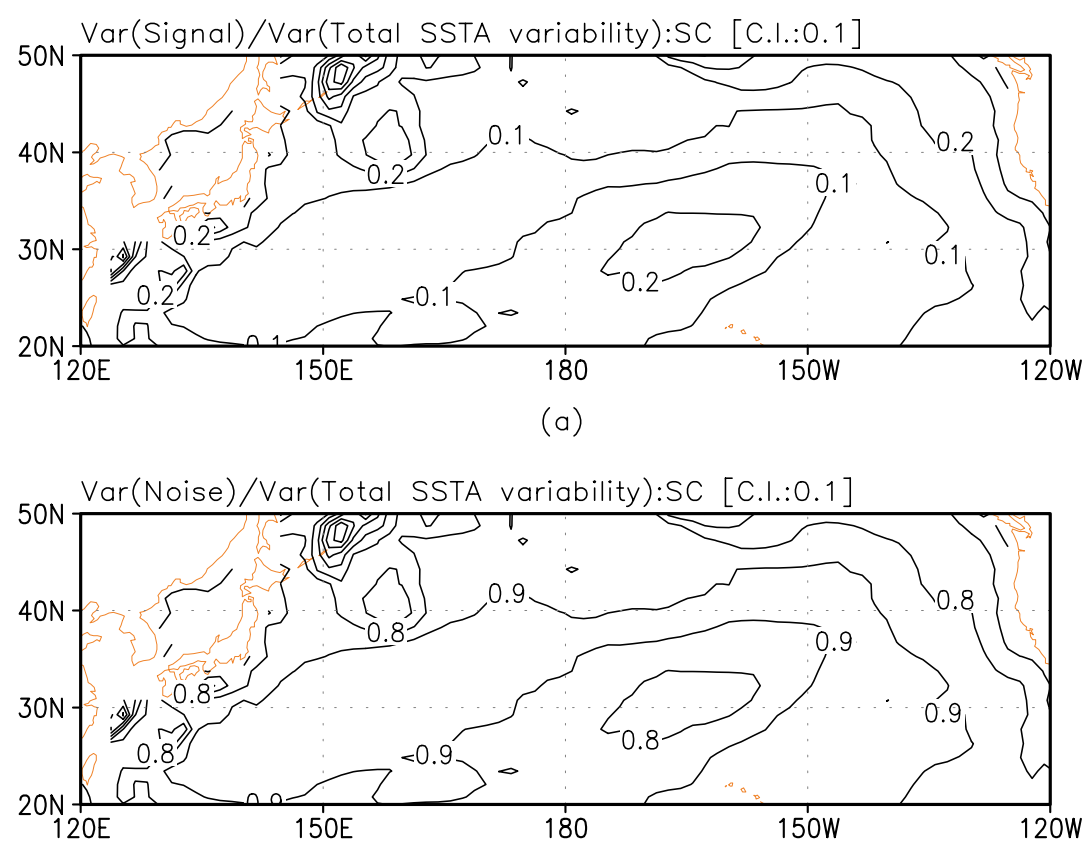

(b)

Figure 3. The ratio of the signal (a) and the noise (b) versus total SSTA variability in the North Pacific in the standard coupled model. Unit is nondimensional. 


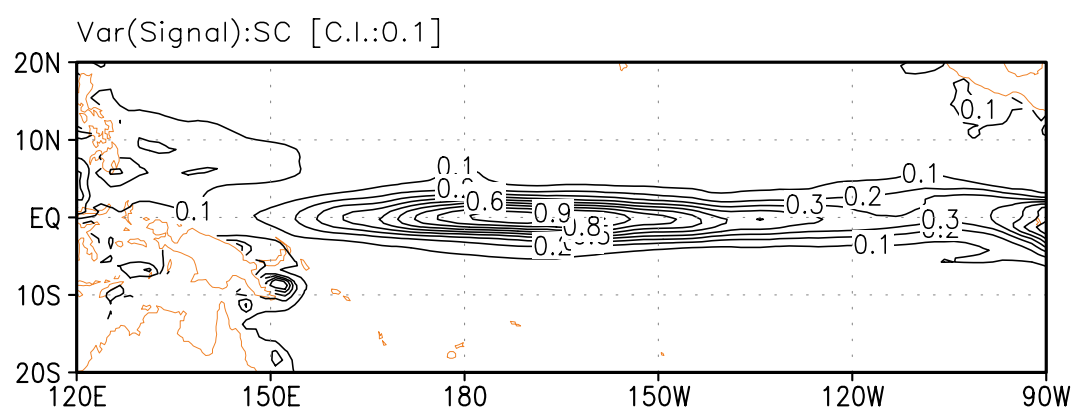

(a)

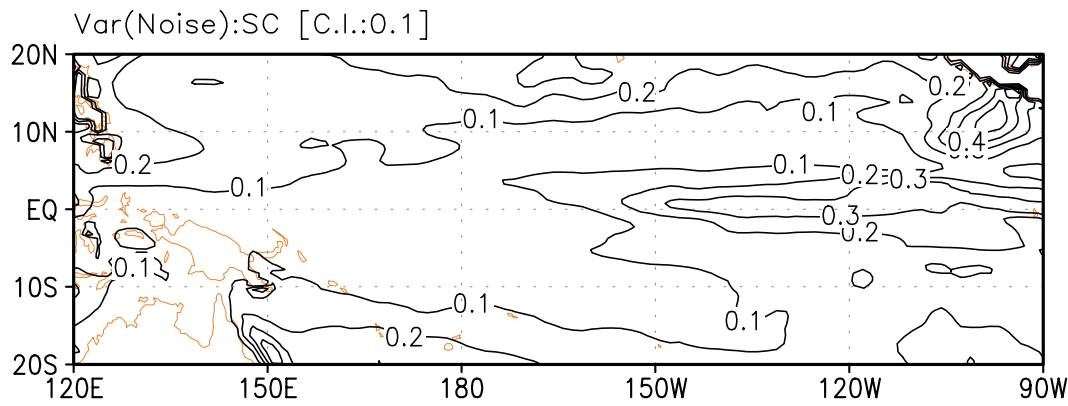

(b)

Figure 4. The spatial pattern of signal (a) and noise (b) SSTA variability for the equatorial Pacific in the standard coupled model. Contour interval is is $0.1\left[{ }^{\circ} \mathrm{C}\right]^{2}$. 

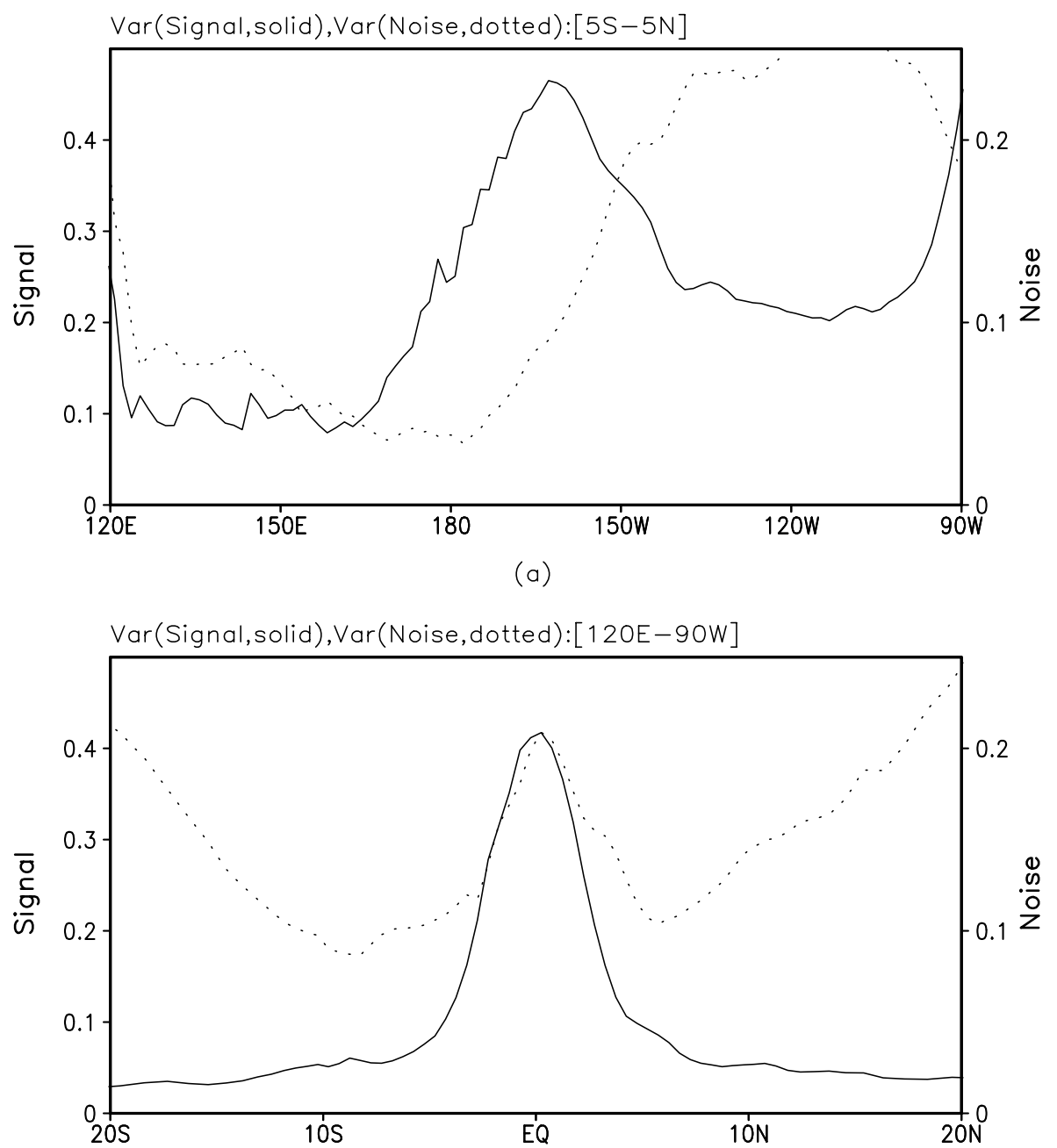

(b)

Figure 5. The signal (solid) and the noise (dotted) averaged in the zonal band $\left(5^{\circ} \mathrm{N}-5^{\circ} \mathrm{S}\right)$ in the equatorial Pacific (a) and (b) as in (a) except for the meridional band $\left(120^{\circ} \mathrm{E}-90^{\circ} \mathrm{W}\right)$. Unit is $\left[{ }^{\circ} \mathrm{C}\right]^{2}$. Note that the amplitude of the signal (noise) is indicated on the left (right) of each panel. 


\section{[Traditional method]}

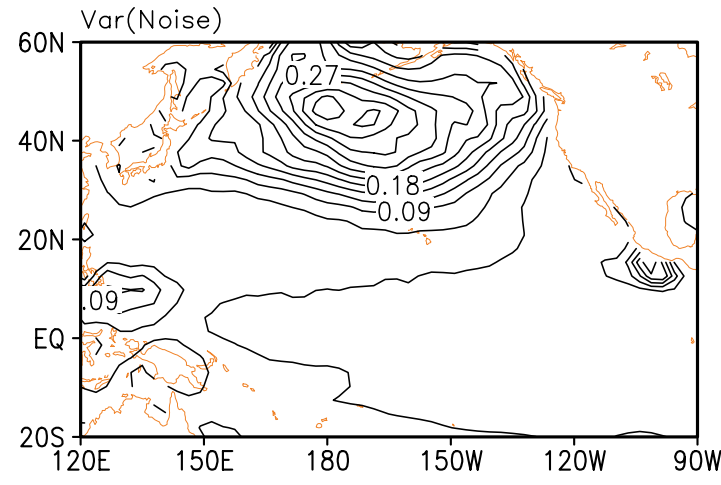

(a)

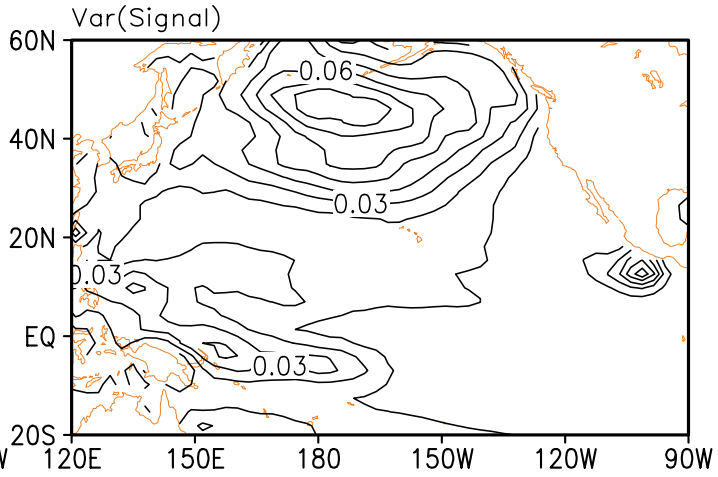

(b)

[New method]

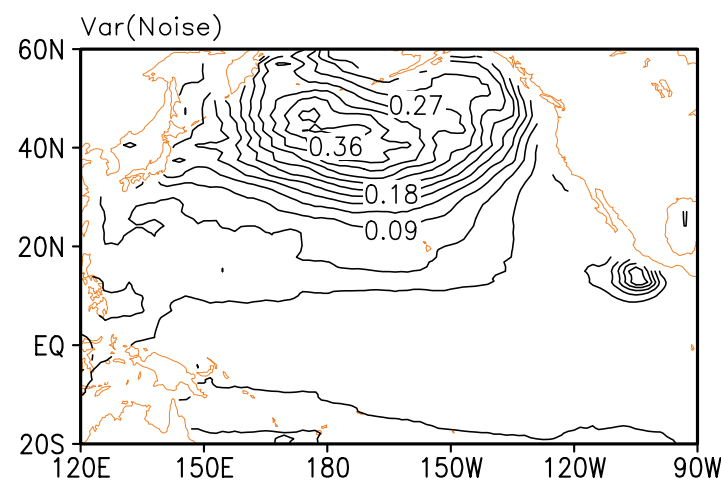

(c)

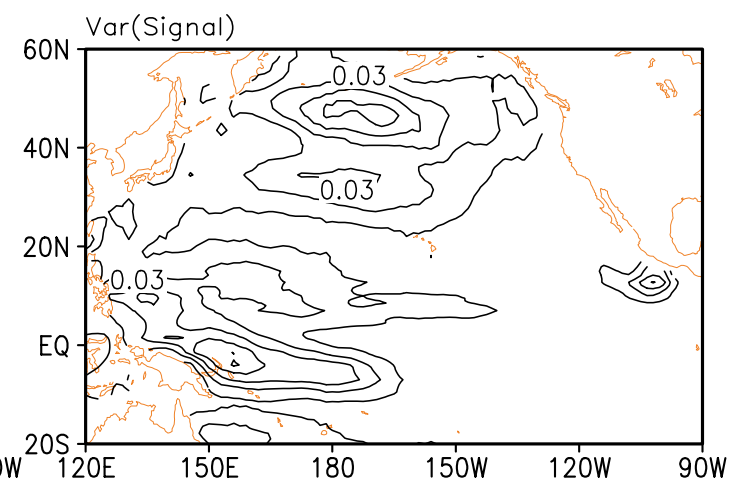

(d)

Figure A1 The noise (a) and signal (b) variability of zonal wind stress based on the traditional method. (c) and (d) as in (a),(b) except for the methodology introduced in section 4. Unit is $\left[\mathrm{dy} / \mathrm{cm}^{2}\right]^{2}$. 